tal and Community Psychiatry 39:628631, 1988

50. Steinbrook R, Lo B, Moulton J, et al: Preferences of homosexual men with AIDS for life-sustaining treatment. New England Journal of Medicine 314:457-460, 1986

51. Simmons-Alling S: AIDS: psychosocial needs of the health care worker. Topics in Clinical Nursing: July 1984, pp 31-37

52. Dunkel J, Hatfield S: Countertransference issues in working with persons with AIDS. Social Worker: MarchApril 1986, pp 114-117

53. Levy RM, Pons VG, Rosenblum ML: Central nervous system mass lesions in the acquired immune deficiency syndrome (AIDS). Journal of Neurosurgery 61:9-16, 1984

54. Schein RHM, Fiscal MA, Pitchenik AE, et al: ICU survival of patients with the acquired immunodeficiency syndrome.
Critical Care Medicine 14:1026-1027, 1986

55. Brenner M, Ognibene FP, Lack EE et al: Prognostic factors and life expectancy of patients with acquired immunodeficiency syndrome and Pneumocystis carinii pneumonia. American Review of Respiratory Disease 136:11991206, 1987

56. Deam R, Kimberly APS, Anderson M, et al: AIDS in ICUs: outcome. Anaesthesia 43:150-151, 1988

57. McCullough P, Cole RP: Prognostic indicators in patients with the acquired immune deficiency syndrome and respiratory infection (abst). Respiration 50:286-293, 1986

58. Wachter RM, Cooke M, Hopewell PC, et al: Attitudes of medical residents regarding intensive care for patients with the acquired immunodeficiency syndrome. Archives of Internal Medicine 148:149-152, 1988
59. Fernandez F, Levy JK, Holmes VF, et al: Critical care issues in HIV-spectrum disorders. Problems in Critical Care 2:159-170, 1988

60. Drane JF: Competency to give an informed consent: a model for making clinical assessments. JAMA 252:925927, 1984

61. Binder RL: AIDS antibody tests on inpatient psychiatric units. American Journal of Psychiatry 144:176-181, 1987

62. Forstein M: HIV testing, in AIDS Primer. American Psychiatric Association AIDS Education Project, Washington, DC, 1988

63. Manula PJ: Protecting confidentiality in the effort to control AIDS. Harvard Journal on Legislation 24:315, 1987

64. AIDS policy: confidentiality and disclosure. American Journal of Psychiatry $145: 541,1988$

\title{
The Management of HIV Infection in State Psychiatric Hospitals
}

Francine Cournos, M.D. Maureen Empfield, M.D. Ewald Horwath, M.D. Martin Kramer, M.D.

Patients with AIDS and related illnesses are entering state mental bospitals in increasing numbers. State bospitals in New York City generally did not plan for patients infected with buman immunodeficiency virus (HIV) un-

Dr. Cournos is director of the Washington Heights community service of the New York State Psychiatric Institute, 722 West 168th Street, New York, New York 10032. Dr. Empfield is clinical director of Creedmoor Psychiatric Center in Queens, New York. Dr. Horwath is director of the community service inpatient unit of the New York State Psychiatric Institute. Dr. Kramer is chairman of the infection control committee at Kingsboro Psychiatric Center in Brooklyn, New York.

Hospital and Community Psychiatry til the first patient appeared; bowever, over the past five years, approaches to managing these patients bave evolved in the areas of admission policies, in-bospital care, and discharge planning. Strentbening infection control procedures through the adoption of universal precautions was the most straightforward aspect of inhospital care. Testing for HIV and confidentiality of the test results proved most controversial. Clinical leaders urged that testing be done only with pre-and posttest counseling and only if the patient has symptoms of HIV infection, has requested the test, or bas exposed others to infection. The authors describe these and other policies addressing medical care, restraint and seclusion, sexual behavior, and education and training.

The management of patients with human immunodeficiency virus (HIV) infection in state hospitals has become an important issue in New York City, which has 24 percent of the United States' AIDS cases (1) and one of the largest urban state hospital systems in the country. New York City has five large state hospitals for adults. Together, these hospitals have about 4,000 beds.

New York's state hospital system managed its first AIDS patient in 1983. In 1986 the system saw 16 newly diagnosed patients with either AIDS or AIDS-related complex, and in 1987 there were 27 new cases (unpublished infection control records, State Psychiatric Centers, New York City, $1986,1987)$. These figures do not include HIV-positive patients who were asymptomatic or had minimal medical symptoms and also do not include patients who were suspected of having HIV infection but who refused the HIV antibody test. This paper discusses problems faced by the state hospitals in New York City in managing patients with HIV infection and describes how management approaches have evolved over the past five years. 
Admission of patients

Planning for the influx of infected patients. By 1983 it had become obvious that the number of AIDS patients in New York City was rapidly growing. Despite the seeming certainty that AIDS patients would eventually be treated in the state hospital system, for the most part the system did no planning until the first patient appeared. The initial patient was a 25-year-old woman who received diagnoses of anemia and leukopenia shortly after admission with a diagnosis of schizophrenia. Those blood abnormalities were at first believed to be caused by the antipsychotic medication she was receiving. The medication was discontinued, but the patient did not improve.

Months later, she was transferred from the state hospital to a general hospital for further evaluation, and diagnoses of pneumocystis carinii pneumonia and AIDS were made. When she was ready to return to the state hospital, one courageous internist accepted her back despite the fears of both staff and administration. Thus we in the state hospital system overcame our denial and acknowledged that we needed to learn how to treat patients with AIDS.

Although there is little formal documentation, anecdotal evidence suggests that the state hospitals in New York City initially refused patients with known HIV infection, so that early cases of AIDS occurred among patients who appeared well at the time of admission or among employees (often homosexual professionals). It is difficult to convey the shock and surprise of hospital staff when these early cases emerged. However, once the system was forced to organize a response, the resistance to accepting infected patients diminished.

Admission criteria for infected patients. In New York, state hospitals have generally been viewed as a place of last resort for patients. Because the state hospital system needs to maintain some control over the flow of patients, admission criteria for HIV-infected individuals have been a persistent preoccupation. The first concern was how much to modify medical clearance criteria that exclude patients who need extensive medical management from admission to the state hospital system.

The daunting task of managing patients carrying the HIV virus and of handling associated opportunistic infections that might need experimental medications has been compounded by the tremendous rise in common infectious diseases that occurred in New York City in association with the HIV epidemic. For example, in the fiveyear period from 1982 to 1987 , the incidence of tuberculosis declined in the United States as a whole, but it rose in New York City by 44 percent. Primary syphilis, which had been stable in the United States during the same period, rose by 75 percent in New York City (1). These illnesses are more contagious than HIV infection and can be spread to patients and employees who are not immunosuppressed.

Becoming responsible for patients with HIV dementia was another worry. In New York State, most institutionalized patients with nonpsychotic dementia are cared for in nursing homes and similar settings $(2,3)$. However, because AIDS patients with dementia are young and more difficult and expensive to manage, these homes have not been receptive to them. In 1987 only .4 percent of New York State's 15,000 hospital discharges of patients with AIDS or other HIV-related illnesses were admitted to nursing homes or other health-related facilities for further management (1). The state hospital system was concerned that it might be forced to change its practice of accepting only patients with dementia who suffered from psychosis or severe behavioral disturbances and for whom management in a psychiatric hospital was essential.

A third area of concern was the management of individuals with known HIV infection who intentionally endanger others. In New York State, it is as yet unclear how such people should be handled and whether public health, criminal, or civil laws will eventually be invoked to contain such individuals. Civil commitment is relatively easy to accomplish, and the use of civil commitment to prevent the spread of HIV infection has been discussed both in the popular press $(4,5)$ and in the psychiatric literature $(6,7)$. State hospitals understandably want to accept responsibility only for patients who are in need of psychiatric hospitalization or who lack the capacity to control their behavior because of a serious mental illness. Because public policy has not evolved to handle the AIDS crisis, we were concerned that state hospitals would be pressured to distort the existing civil commitment laws to admit HIV-positive patients who endanger others.

Although admission criteria for AIDS patients are still in a state of evolution, we have found the most appropriate approach has been to refuse to allow the presence of HIV infection to destroy long-established principles. We have attempted to preserve the usual psychiatric criteria for admission-presence of severe psychotic illness or behavioral disturbance requiring hospital care. We then consider whether patients' psychiatric needs predominate over their need for medical care that might be better delivered in a general hospital's medical ward.

However, adhering to this approach is not in any way simple. We are pressured to accept patients who are referred from overwhelmed general hospitals as well as from the forensic system (8). These patients, once admitted, may rapidly become terminally ill. We have discovered that panic, desperation, ignorance, good will, and self-righteousness often interfere with sensible judgment.

\section{In-hospital care}

Infection control. Infection control proved to be the most straightforward aspect of the management of HIV. In all health care settings the adoption of universal precautions for infection control has 
greatly diminished the need to consider routine testing and segregated care as necessary components of management. Universal precautions also allow a more appropriate focus on preventing transmission of the virus by the large number of unidentified carriers $(9,10)$. In addition, these precautions help prevent the spread of other more easily transmissible diseases such as hepatitis B.

In effect, it is possible to provide integrated care and maintain the confidentiality of patients' HIV antibody status by managing all patients as if they had the potential for transmitting the virus. This practice allows us to base recommendations for HIV antibody testing on clinical need and to make decisions about designating AIDS wards based purely on whether they contribute to efficient clinical operations. In the state hospitals in New York City, we have concluded that resources are best used by providing integrated care and that such an approach prevents the false belief that we can differentiate between infected and uninfected individuals. The procedures for implementing universal precautions are clear, and we have largely depended on guidelines issued by the Centers for Disease Control (CDC) (11-15).

Testing and confidentiality. Policies governing HIV testing and confidentiality of the test results are the most controversial components of in-hospital management. A majority of the clinical leaders in our system concluded that testing should be done only with preand posttest counseling, and only if the patient has clinical signs and symptoms suggestive of HIV infection, has a history of risktaking behavior and voluntarily requests the test, or has exposed either a health care worker or another patient to infection through a needle stick, sexual assault, or other circumstances.

Our strong sentiment against routine testing is influenced by the limited therapeutic benefits of test results for patients, as well as by the test's potentially harmful effects, including adverse psychological reactions, stigma, and dis- crimination in the community (16). The risks and benefits are, of course, constantly changing and will be modified by scientific, social, and political developments.

In New York State, HIV antibody testing requires informed consent (17). We have not yet taken any patient to court to obtain permission to test over the patient's objection. When a patient does not refuse the test but lacks the capacity to consent, we consider testing if it appears to be vital to diagnosis or medical treatment, but not if the test is requested by a third party, for example, by a staff member who has been stuck with a needle containing the patient's blood. In such cases, we assume the patient's blood is HIV-positive and suggest the employee be tested and counseled following CDC guidelines.

In New York State, testing is confidential, but the state department of health also mandates that the results be placed in patients' charts (17). In a state hospital, the confidentiality of information placed in a chart is severely limited since hundreds of staff potentially have access to it. Moreover, many of our patients openly discuss the results of their HIV test with staff, fellow patients, and family members. This openness may be a result of our patients' degree of dependency and impairment. Often patients need advice about when not to disclose the results of testing. Because confidentiality is not consistently achievable in the state hospital setting, we consider it our responsibility to inform appropriate patients of the alternative of anonymous testing after discharge at department of health test sites.

Balancing the patient's right to privacy against the physician's duty to warn endangered third parties has not in most instances been an issue-either the patient refuses testing or agrees to it and is willing to discuss the results openly. If the question arises, we will make decisions about warning third parties on a case-by-case basis. However, since February 1, 1989, when New York State's HIV Testing and Confidentiality Statute (18) went into effect, physicians have been permitted, but not required, to warn patients' known contactseither sexual or needle-sharing partners-who are at risk of contracting HIV. During such notifications, the identity of the infected patient is not revealed. Physicians cannot be held civilly or criminally liable for disclosures made in accordance with the statute.

Medical care. In recent years, state hospitals in New York have phased out some of their medical responsibilities and have worked to create stronger agreements with general hospitals for the services that have been eliminated. The HIV epidemic has caused us to reconsider the appropriateness of this plan. As noted, state hospitals in New York City have eased medical clearance criteria to manage patients with HIV infection. This policy has produced some unexpected successes in the care of these patients, but also has presented substantial difficulties.

The day-to-day management of patients with recurrent fevers, multiple infections, malignancies, and agitated dementia requires frequent, even daily, attention from internists and other medical staff. It is impractical for a state hospital to provide this kind of care unless physicians are on the hospital's own professional staff. Even if medical care is available at a state hospital, a good relationship with a general hospital must be maintained to meet crises that cannot be handled on site. These relationships are also important because patients who appear only mildly ill on admission may rapidly deteriorate to a terminal phase of the illness over a period of weeks or months.

Restraint and seclusion. We have made modifications in our procedures for restraint and seclusion in an attempt to increase safety for clinical staff and security officers. We attempt to intervene early in cases of agitation, and we concentrate on good head control during restraint to minimize the chance of a patient's biting a staff member. We are also experimenting with 
the use of gloves and restraining blankets to reduce the chance of staffs being bitten. To prevent needle stick injuries during emergency parenteral injections for agitation, we use restraint where appropriate and needles that are automatically covered by a plastic sheath upon withdrawal.

Sexual behavior. Sexual activity among seriously ill psychiatric patients has, for the most part, received insufficient attention. The HIV epidemic is forcing us to confront this issue. We now require an assessment of each patient's risk-taking sexual behaviors and of his knowledge of safer sexual practices.

While the hospital recommends abstinence from sexual activity for inpatients, we recognize that sexual impulses are a powerful force. Newly admitted patients who are hypersexual or impulsive due to an acute mental illness such as mania and patients who are chronically regressed and disinhibited should be prevented from having sex and should be placed on wards that are sufficiently well staffed to make this possible. These precautions are critical, not only to prevent HIV infection but also to protect patients lacking in judgment and impulse control from venereal diseases, pregnancy, and sexual activity to which they have not consented.

The most difficult group to monitor will be inpatients who have sufficient remission of symptoms to attend programs independently. This group includes forensic patients and patients awaiting placement. The ability to appropriately manage sexual activity and to avoid unsafe sex must be a criterion for granting unescorted passes. Condoms should be readily available to patients leaving the facility on pass. Staff should be prepared to encourage patients' reporting of unwanted sexual advances and to intervene to protect patients.

Education and training. No policy can be implemented without adequate education and train- ing for staff and patients, a fact that has been repeatedly emphasized in papers concerning the management of HIV infection (1922). This undertaking is of considerable magnitude in state hospitals, often involving thousands of staff and patients. A comprehensive educational plan, beginning with senior management and proceeding through each ward and department, must be established.

The plan must provide ongoing education and must reach every employee, including employees who are only remotely involved in patient care, such as housekeeping and dietary staff. Employees need time to ask questions, learn the facts about the nature of the disease and its transmission, and resolve emotional issues $(19,20,23,24)$. Education must also be tailored to particular employees' tasks. For example, physicians need training in the recognition of the early infectious and neuropsychiatric manifestations of the illness, and security officers need information on how to respond to violence without endangering themselves.

We believe the use of speakers from outside agencies lessens the degree of suspicion employees may have about getting falsely reassuring information from hospital management. We use a large array of booklets and videotapes produced by such organizations as the Gay Men's Health Crisis, the Red Cross, and city and state departments of health and education. Patients also need education, which should include individual counseling and group education about infection control and preventing the spread of HIV and other sexually transmitted diseases. Educational efforts aimed at intravenous drug users should encourage control of the addiction, elimination of needle sharing, and, if all else fails, use of bleach to clean needles.

Costs. The cost of responding to the HIV epidemic will be considerable. Increased costs can be expected for education and train- ing, equipment for universal precautions, drugs such as zidovudine (formerly called AZT), increased staffing to improve medical care and patient supervision, and increased hospital census as difficultto-discharge HIV-infected patients enter the system.

\section{Discharge of patients}

A positive HIV antibody test, with or without associated medical problems, has an enormous impact on the discharge planning process. The potential dangerousness of HIV-positive patients, discrimination against them, and a lack of suitable placements are the three major concerns.

We believe that state hospitals should not be used to detain HIVinfected people who might spread the disease but who are competent and otherwise ready for discharge. However, this is not the usual situation we face. Instead, some of the patients we judge to be at risk of spreading infection are unwilling to comply with psychiatric treatment and have a history of poor judgment and risktaking behavior during relapse. Others have totally unrealistic ideas about whether they can transmit the infection to other people. $\mathrm{Pa}$ tients may also endanger themselves by ignoring their physical condition and failing to seek needed medical attention.

Discharging such patients without very careful supervision poses an enormous ethical problem. In planning the patient's outpatient care, our practice is to obtain the patient's cooperation in sharing information about positive HIV test results with others who will need it, usually a family member, an aftercare provider, or both.

On the other hand, revealing the patient's HIV status can significantly undermine options for discharge. Some families are too frightened to accept the patient back home. In New York City providers of virtually every type of residential placement have expressed concern about admitting these patients, and many have sim- 
ply refused to accept them. Some initially asymptomatic patients in residential programs have developed HIV illnesses and deteriorated to the point of requiring constant medical attention well beyond the capacity and resources of the program. These experiences can discourage providers from accepting infected patients or even seemingly healthy patients who are in known risk groups.

Future directions. In the future, it will be essential that we respond to the dearth of long-termcare placements for HIV-infected patients in general and for HIVinfected patients with combined medical and psychiatric problems in particular $(9,16,25)$. Many of the suggested solutions involve models that the field of psychiatry has helped to pioneer during its long struggle to create a continuum of services to replace costly and more restrictive hospital care. They include such interventions as outreach, case management, day hospitalization, and supervised residential settings $(9,10,26,27)$. We believe that using the generic health care system to provide medical and psychiatric care for most patients with HIV-related illness and creating specialized programs only for those who absolutely need them is the least discriminatory and most economically feasible alternative.

To achieve these aims, we need to train providers in the community, offer them realistic financial incentives, and work to overcome their tendency to discriminate against these patients. Because these patients have multiple needs-for physical and mental health services, legal services, and financial assistance-using case management to connect them to an array of services seems particularly appropriate.

However, we also believe that even after these steps are taken, we will still need to create programs that offer integrated medical and psychiatric treatment in a continuum of settings, including the home and other residential settings. We feel that some important demonstration projects could be established in this area, and that successful programs for HIV-infected state hospital patients could become important models for the care of all patient populations with combined medical and psychiatric disorders.

\section{Acknowledgments}

The authors thank Stephan Haimowitz, J.D., John Oldham, M.D., and Kurt Patton, M.S.

\section{References}

1. AIDS in New York State. Albany, State Department of Health, 1988

2. Goldman $\mathrm{HH}$, Adams NH, Taube CA: Deinstitutionalization: the data demythologized. Hospital and Community Psychiatry 34:129-134, 1983

3. Persons in institutions and other group quarters, in 1980 Census of Population, Subject Reports, Vol 2. Washington, DC, Bureau of the Census, Oct 1984

4. McFadden RD: Boy, 14, is put in psychiatric ward after report of AIDS exposure. New York Times, June 12, 1987, p B4

5. Down J: Laws allow little action against AIDS carrier. Plattsburgh, NY, Press Republican, July 10, 1987, p 1

6. Appelbaum PS: AIDS, psychiatry, and the law. Hospital and Community Psychiatry 39:13-14, 1988

7. Cournos FC, Horwath E: Confining AIDS patients (ltr). Hospital and Community Psychiatry 39:671, 1988

8. Wormser GP: AIDS in prisons, in AIDS and Other Manifestations of HIV Infection. Edited by Wormser GP. Park Ridge, NJ, Noyes, 1987

9. Weinberg DS, Murray HW: Coping with AIDS: the special problems of New York City. New England Journal of Medicine 317:1469-1472, 1987

10. Alderman MH, Drucker EE, Rosenfeld $A$, et al: Predicting the future of the AIDS epidemic and its consequences for the health care system in New York City. Bulletin of the New York Academy of Medicine 64:175183,1988

11. Centers for Disease Control: Acquired immunodeficiency syndrome (AIDS): precautions for clinical and laboratory staffs. Morbidity and Mortality Weekly Report 31:577-580, 1982

12. Centers for Disease Control: Acquired immunodeficiency syndrome (AIDS) precautions for health-care workers and allied professionals. Morbidity and Mortality Weekly Report 32:450-452,
1983

13. Centers for Disease Control: Recommendations for preventing transmission of infection with human T-lymphotropic virus type III/lymphadenopathyassociated virus in the work place. Morbidity and Mortality Weekly Report 34:681-695, 1985

14. Centers for Disease Control: Recommendations for the prevention of HIV transmission in health care settings. Morbidity and Mortality Weekly Report 36 (Suppl 2):1-18, 1987

15. Centers for Disease Control: Update: universal precautions for prevention of transmission of human immunodeficiency virus, hepatitis $B$ virus, and other bloodborne pathogens in health care settings. Morbidity and Mortality Weekly Report 37:377-382, 1988

16. Binder RL: AIDS antibody tests on inpatient psychiatric units. American Journal of Psychiatry 144:176-181, 1987

17. A Physician's Guide to AIDS: Issues in the Medical Office. Albany, New York State Department of Health, Mar 1988

18. Ch 584,1988 NY Laws

19. Polan HJ, Hellerstein D, Amchin J: Impact of AIDS-related cases on an inpatient therapeutic milieu. Hospital and Community Psychiatry 36:173-176, 1985

20. Amchin J, Polan $\mathrm{HJ}$ : A longitudinal account of staff adaptation to AIDS patients on a psychiatric unit. Hospital and Community Psychiatry 37:12351238, 1986

21. DesJarlais DC, Tross S, Friedman SR: Behavioral change in response to AIDS, in AIDS and Other Manifestations of HIV Infection. Edited by Wormser GP. Park Ridge, NJ, Noyes, 1987

22. Faulstich ME: Psychiatric aspects of AIDS. American Journal of Psychiatry 144:551-556, 1987

23. Rosse RB: Reactions of psychiatric staff to an AIDS patient (ltr). American Journal of Psychiatry 142:523, 1985

24. Cummings MA, Rapaport M, Cummings KI: A psychiatric staff response to acquired immune deficiency syndrome (Itr). American Journal of Psychiatry 143:682, 1986

25. Baer JW, Hall JM, Holm K, et al: Challenges in developing an inpatient psychiatric program for patients with AIDS and ARC. Hospital and Community Psychiatry 38:1299-1303, 1987

26. Watkins JD: Presidential Commission on the Human Immunodeficiency Virus Epidemic, Chairman's Recommendations. Washington, DC, US Government Printing Office, Feb 29, 1988

27. Health Care Forum, CIBA-GEIGY Corp: An action plan for the future. Presented at a conference on the management of the AIDS patient in hospital and outpatient settings, San Francisco, Mar 16-18, 1988 